\title{
¿ALEJANDRÍA O ÁFRICA? AMBIGÜEDAD Y AMBIVALENCIA
}

\author{
POR
}

\author{
FABIOLA SALCEDO GARCÉS \\ Escuela Española de Historia y Arqueologia. ('SIC, Roma
}

\section{RESUMEN}

La personificación de Alejandria puede representarse, en ocasiones, como la provincia romana de Africa. Por esta razón, ambas imágenes se han confundido frecuentemente, como en los casos que presentamos.

La autora trata de analizar el origen y razón de esta identidad iconográfica y propone como factor diferenciador el origen étnico del receptor de la imagen.

\section{SUMMARY}

The personification of Alexandria can occasionally be represented as the Roman Province of Africa. Because of this. both images have been frecuentely confused, as in the cases here presented.

The author of this paper tries to analyse the origin and reason of this iconographical identity and also proposes that the distinguishing factor is directly related with the ethnic origin of the image's receiver.

Me resulta significativo encabezar este artículo parafraseando uno ya clásico y célebre de E. Babelon cuyo título evidenciaba el conflicto entre dos imágenes casi idénticas '. Esta misma duda, trasladada ahora al binomio Africa-Alejandria, ha planeado como una sombra, durante casi setenta años, sobre numerosos estudios parciales o globales sobre el tema. Consciente de la dificultad que encierra el problema de identificación iconográfica entre una imagen $y$ otra, es mi objetivo en este trabajo ofrecer una posible solución al mismo.

\footnotetext{
' Babelon, E., «Alexandre ou l'Afrique?. Etude d'iconographie d'aprés les medailles et les pierres gravées», Aréthuse I, 1924, pp. 95-107.
}

La ciudad de Alejandria estuvo representada en época romana a través de diversas personificaciones, además de por las divinidades protectoras por antonomasia de la ciudad: Isis y Serapis. Las primeras imágenes de Alejandria parecen haber sido las representadas en dos mosaicos encontrados en Tell Timaï en los que aparece una personificación femenina tocada con una proa de navio. Uno de ellos, firmado por Sophilos, está fechado hacia el 200 a.C.; el segundo, de autor anónimo, se realizó hacia mediados del siglo II a.C. ${ }^{2}$ La identificación de ambas imágenes con Alejandría se puso en duda, no obstante, tras observar que ambos constituyen sendos retratos de reinas helenísticas, lo cual, desde mi punto de vista, no invalida su defínición como la capital egipcia. No son pocos los casos en los que los monarcas helenísticos se identifican con la figura de alguna divinidad o personificación; además, ambas figuras están tocadas con sendas proas de navío, símbolo de ciudad costera que acompañará a la personificación de Alejandría hasta el siglo iv d.C. ${ }^{3}$.

Esta alusión al carácter portuario de la ciudad constituye, por tanto, uno de los tipos iconográficos de Alejandria, al que denominamos «naval».

\footnotetext{
:Ambos mosaicos realizados en opus vermiculatum y descubiertos en Thmouis (Tell Timai, en la zona del Delta del Nilo). Alejandria, Museo greco-romano, 21736 y 21739 . En general, sobre la iconografia de Alejandria, ver Jentel 1981, p. 492, $\mathrm{n}^{\circ}$ 73 y 74 , quien clasifica ambas imágenes como dudosas; ver también Daszewski 1986, pp. 299-301.

' Por ejemplo, la imagen del calendario de 354 d.C., conocido por un dibujo del siglo XVII. Alejandría aparece de pie, coronada de espigas y dos barcos al fondo, Stern, H., Le calendrier de 354, 1953, 139-142, pl. II. Salzman, M.R., On Roman Time. The Codex-Calender of 354 and the rhythms of urban life in late antiquity. Univ. of California Press, Oxford 1990, pp. 2627. Jentel 1981, p. 492, n62; Daszewski 1986, p. 305, fig. 8.
} 
En la $1^{\text {a }}$ mitad del siglo I a.C... entra en escena otro tipo iconográfico de Alejandria, cuya extensión temporal superará a los anteriores, ya que será representado hasta el siglo i d.C. El elemento definidor de esta otra imagen es la corona mural.

La primera vez que vemos esta Alejandria torreada es en los denarios republicanos acunados por M. Aemilius Lepidus (72-50 a.C. $)^{4}$, y no la volveremos a encontrar hasta el 112 d.C., en las monedas de Trajano. Alejandría se presenta entonces en una escena de sacrificio junto al emperador, que realiza una libación sobre un altar ${ }^{`}$. La misma fórmula es utilizada en monedas de Cómodo ". La personificación viste ahora quitón largo y manto, respondiendo asi a la imagen de la Tyche de Antioquia ${ }^{7}$. Desde el punto de vista plástico, el tipo de corona puede ser muy elaborada, como en el caso de los denarios de Lépido o de la estatuilla en plata encontrada en el Esquilino (Roma, fin del siglo iv o principios del $v$ d.C. $)^{\times} \mathrm{o}$, por el contrario, constituir un simple bonete de torres esquemáticas, como sucede en la mayoria de los casos.

Paralelamente a estas imágenes, aparecen otras en las que Alejandría va tocada con una flor de loto ${ }^{9}$, espigas ${ }^{10} \mathrm{o}$ simplemente, sin tocado ${ }^{11}$.

Los atributos que acompañan estos tipos de Alejandría expresan la dicotomía guerra-fertilidad propia de las personificaciones territoriales, a través de distintos mensajes:

a) El triunfo: palma, corona, vexillum.

b) El dominio: cetro.

c) La riqueza agrícola: espigas y frutos.

En cuanto a los elementos que la afilian al mundo egipcio están presentes diversos símbolos de la fauna y flora del pais, como el cocodrilo, las uvas, así como otros de carácter religioso ${ }^{12}$, algunos de

${ }^{4} B M C R R$ I, $\mathrm{n}^{\circ} 449 ; \mathrm{III}, \mathrm{n}^{\circ} 3648-3649 ; R R C, \mathrm{n}^{\circ} 419 / 2$.

5 Dattari 1901, n० 783, pl. VIII.

- BMC Alexandria n ${ }^{\circ}$ 1435-1436, pl. xxvii.

Gardner 1888, 47 ss.

* Hoy en el Museo Británico, Londres. EC 335. Gardner 1888. 47. pl. V; Painter, K.S., Wealth of the Roman World, Gold and Silver $A D$ 300-700. Expo London 1977, 49, $\mathrm{n}^{\circ} 97$.

${ }^{9} \mathrm{~S} / \mathrm{Roma} /$ Antonino Pío, 139 d.C., BMCRE IV, n¹179, pl. 26; RIC 1II, p. 104, n०577, 578; p. 106, n 593.

to Representación del Calendario-códice del 354 d.C., ver supra, nota 3.

11 Como en el fresco mural de la Casa de Meleagro, en Pompeya, en el que la figura central ha sido interpretada como Alejandria. A pesar de que porta una situla, Jentel 1981, pp. 488494 , la cla sifica como carente de atributos. Ver supra p. 4.

12 Existen otros tipos femeninos con atributos isíacos, que bien podrian ser interpretados como Alejandria y/o Isis, ver Jentel 1981, p. $492, \mathrm{n}^{\circ} 75-78$. los cuales toma prestado de la personificación de Egipto ${ }^{13}$ : busto de Serapis con el modius, vaso coronado por un disco solar ${ }^{14}$, el sistro y la situla con uraeus $^{15}$.

Junto a estos tipos iconográficos, existe otro heredero directo de las imágenes de Alejandro Magno y definido por la posesión de un atributo: las exuviue elephantis. Este elemento, que comparte con la personificación de la provincia romana de Africa, ha sido la causa de definir como Alejandría imágenes que, en mi opinión, no lo son ${ }^{16}$. Será, por tanto, esta fórmula visual la que ocupará nuestra atención en las páginas que siguen.

La primera imagen - del tipo que denominamos "alejandrino», por su derivación de la imagen de Alejandro - comúnmente aceptada como personificación de Alejandria es la que aparece en las acuñaciones neronianas del $65 / 66$ d.C. ${ }^{17}$ y seguirá representándose hasta el siglo III d.C., siempre en alternancia con los otros tipos iconográficos señalados más arriba ${ }^{18}$. (fig. 1).

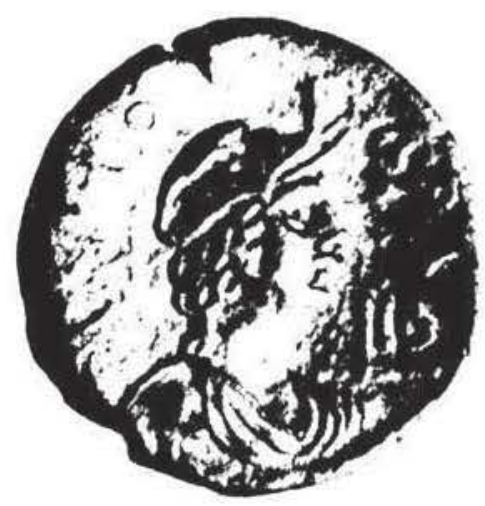

Figura 1.-Tetradracma de vellón ( 25 y $22 \mathrm{~mm}$ ). Alejandria. Nerón, 65-66 d.C. (Foto LIMC).

\footnotetext{
13. Toynbee 1934, p. 28 y ss.

14 Todas acuñadas en Alejandria: AE/ Marco Aurelio, 164 165, Dattari 1901, n³426, pl. VIIl; AE/ Septimio Severo, 201 202, Dattari 1901, n 4009 bis; Bi/Eliogábalo, 218-219, Dattari 1901, $\mathrm{n}^{\circ} 4100$; Bi/ Severo Alejandro, 231-234, BMC Alexandria ${ }^{\circ} 1690$; AE/Filipo I, 246-250, BMC Alexandria $n^{\circ} 1988-1989$; AE, Bi/ Valeriano, 257-260, Dattari 1901, n5144, pl. VIIl; Bi/ Aureliano, 270-272, BMC Alexandria $\mathrm{n}^{\circ} 2352$; Bi/Diocleciano, Maximiano, 285-293, BMC Alexandria $\mathrm{n}^{\circ} 2529-2530$. Jentel 1981 , p.491, n० 52-59.

is AR/ Roma/ Adriano, 134-138 d.C., BMCRE III, n 823, pl. 3, 5, n० 824-828; RIC II, p. 374, n³00, pl. XIII, 267.

16 Sobre el origen de las exuviae elephantis, ver Salcedo 1991 , 284 ss.; Stribrny,K., "Zur Entstehung der Elefanten-Exuvie als "África»-Attribut», Festschrift für Maria R. Alföldi, Die Münze. Bild - Botschaft - Bedeutung. Frankfurt 1991, pp. 378-385, ambos con bibliografia anterior.

17 BMC Alexandria ${ }^{\circ} 163-164, \mathrm{pl}$. XXIV.

18 Contrariamente a Jentel (1981) y de acuerdo con Daszewski (1986), no considero como Alejandría las efigies femeninas representadas en las monedas chipriotas de Paphos del 117 a.C. La leyenda reza claramente Basilises Kleopatra.
} 
A partir de este momento, ef conflicto visual con la imagen de África está abierto y es ahora cuando propongo una diferenciación entre ambas basándonos en dos distintas categorías de criterios: 1) de carácter puramente plástico, y 2) de carácter iconológico. Es en este último donde intervienen el factor histórico y el politico-propagandistico. Comencemos con los primeros.

$\mathrm{Si}$ analizamos detalladamente las imágenes en busto de Alejandría en la numismática ${ }^{14}$, observaremos que las exuviae elephantis tienden a ajustarse totalmente a la cabeza, formando casi un bonete que deja ver el rico peinado de rizos. Pero si bien en estas representaciones cabe la posibilidad de confusión, no ocurre lo mismo en las de cuerpo entero. En ellas, a diferencia de África, que viste quitón largo, Alejandria se presenta siempre en atuendo de amazona: quitón corto, clámide y endomys ${ }^{20}$. Puede aparecer aislada ${ }^{21} \mathrm{o}$ acompañada de diversos personajes: a) con el emperador, en gesto de coronación ${ }^{22}$, adventus ${ }^{23}$ o reverencia ${ }^{24}, \mathrm{y}$ b) con Neilos y Roma, en gesto de saludo, señalando así su vinculación mitica con el primero y su relación de igualdad con la segunda ${ }^{25}$.

El problema se plantea cuando tenemos imágenes en busto representadas en soportes iconográficos no numismáticos y carentes de leyendas alusivas. Es entonces cuando entran en juego otros argumentos de carácter histórico, y nuevamente es la numismática la que nos brinda la clave de interpretación.

${ }^{19} \mathrm{Bi} / \mathrm{Galba}, 68-69$ d.C., BMC Alexandria $\mathrm{n}^{\circ}$ 199-200; Bi/Otón, 69 d.C., idem $\mathrm{n}^{\circ} 212$, pl. XXIV; AE/Vespasiano, $75-77$ d.C., Dattari 1901, $\mathrm{n}^{\circ} 367, \mathrm{pl} . \mathrm{VIII}$; AE/Domiciano, 82-85 d.C., BMC Alexandria $\mathrm{n}^{\circ} 310-311, \mathrm{pl}$. XXIV; Bi/Trajano, 102-103 d.C./ II1-112. Geissen, AlexKaisermünzen I, $n^{\circ} 454,573 \mathrm{n}^{\circ} 654$, pl. XXIV; $\mathrm{Bi}$ / Adriano, 119-126 d.C., Geissen, idem II, $\mathrm{n}^{\circ} 783,822,848,896$. 937; Bi/Adriano, 125-126, 131-132 d.C., BMC Alexandria n ${ }^{\circ} 654$, pl. XXIV; AE/ Antonino Pio, 157-159 d.C., idem n ${ }^{\circ} 1170, \mathrm{pl}$. XXIV.

${ }^{20}$ Monedas de Vespasiano, 68-71 d.C.; Antonino Pio, 150151 d.C.; Severo Alejandro, 231-232; Filipo I, 246-248; Julia Mamea, 230-231 d.C., ver BMC Alexandria, passim.

${ }_{21} \mathrm{Bi} /$ Vespasiano,68-71 d.C., BMC Alexandria, $\mathrm{n}^{\circ} 244 ; \mathrm{Bi} /$ Antonino Pio, 150-157 d.C., idem $\mathrm{n}^{\circ}$ 998, pl. XXIV; Bi/Severo Alejandro, 231-232 d.C., idem $\mathrm{n}^{\circ} 1687 \mathrm{pl}$. XXIV; Bi/Filipo I, 246-248 d.C., idem; Bi/Julia Mamea, 230-231 d.C., idem $\mathrm{n}^{\circ} 1796$ pl. XXIV. 529.

${ }_{22}$ AE/Trajano, 112-113, 114-115 d.C., BMC Alexandria, $\mathrm{n}^{\circ}$

23 Bi/Adriano, 130-131, BMC Alexandria n ${ }^{\circ} 669$; Bi/Septimio Severo, 199-200 d.C., Milne,J.G., Catalogue of Alexandrian Coins, Oxford 1971, $\mathrm{n}^{\circ} 2723$. Sobre las series que se emiten para conmemorar el viaje de Adriano a Alejandria, que tuvo lugar en el 130-131 d.C., ver Toynbee 1934, p. 39 ss.

${ }^{24} \mathrm{Bi} /$ Cómodo, 185-186 d.C., Dattari 1901, n 3855.

25 AE/Trajano, 107-108 d.C., Dattari 1901, n० 794 pl. VIII; AE/ Trajano, 112-113 d.C., idem, $n^{\circ} 1008$, pl. XX. Neilos es el personaje mítico fundador de Mileto, ciudad que estuvo bajo el dominio de los Ptolomeos.
Todas las series monetales en las que aparece la figura de Alejandria, tanto en su tipo alejandrino, es decir, con exuviae elephantis, como en casi todos los demás, fueron acuñadas en Alejandria y destinadas a la circulación local o provincial ${ }^{26}$. Esta situación hay que entenderla dentro del marco histórico general del Egipto romano.

$\mathrm{Si}$ bien puede resultar excesivo, como ha mantenido la historiografia hasta hace poco tiempo, considerar Egipto como una propiedad personal del Emperador ${ }^{27}$, lo cierto es que esta provincia desempeñó un papel excepcional con respecto al resto del imperio ${ }^{28}$. Expresión directa de esta voluntad de mantener parte de la tradición lágida fue el carácter de la moneda. Augusto, al final de su reinado, reactivó la ceca de Alejandria acuñando monedas en bronce que, continuando la tradición de las últimas series numismáticas de Cleopatra, basaban su metrología en la dracma griega y sus fracciones ${ }^{29}$. Tanto estos bronces como la plata, que a partir del séptimo año del reinado de Tiberio ( 20 d.C.) vuelve a emitirse con la denominación tetradracma de vellón ${ }^{30}$, serian exclusivamente de circulación egip$\mathrm{cia}^{31}$. Con ello se evitaban posibles fluctuaciones de su valor a causa de los mercados exteriores, convirtiéndose en moneda fiduciaria, sujeta a continuas devaluaciones ${ }^{32}$. Las tasas y otros impuestos con los que Egipto debía contribuir al Estado los realizaba sobre todo en especias, trigo y aceite, principalmente ${ }^{33}$. Por su parte, los comerciantes que en-

26 RIC 1, p. 19. Ver también Vogt, J., Die alexandrinischen Münzen, vol. 1, Stuttgart 1924.

27 Tácito, Hist. I, 11. Sobre lo que supuso la era augustea frente a la tradición ptolemaica en Egipto, ver Bowmann/Rathbone 1992, p. 111.

${ }^{2 \times}$ Dos de las peculiaridades más sobresalientes que la diferenciaban del resto de las provincias eran: 1) el gobernador no pertenecia al rango senatorial, sino al ecuestre; 2 ) los senadores romanos tenian prohibida la entrada en Egipto a no ser con el permiso explicito del emperador, quizá como prevención ante el levantamiento de otro Antonio o bien para evitar la adquisición de propiedades por parte de aquéllos. Ver Bowman/Rathbone 1992, p. 110.

${ }_{20}$ Curtis, J. W., The Tetradrachms of Roman Egypt, Chicago 1969 , p. IX.

${ }^{30}$ Crawford ,M.H., Coinage and money under the Roman Republic, 1985, p. 271-2.

${ }^{31}$ En época de Diocleciano es cuando se abolirá el privilegio de la ceca de Alejandría, Bowman/Rathbone 1992, p. 114; Curtis, j.W., The Tetradrachms of Roman Egypt, 1957, p.3.

${ }^{32}$ Las tetradracmas de Tiberio tenían un $25 \%$ de plata; Nerón redujo la proporción a un $16 \%$; Marco Aurelio, a un $6 \%$ y finalmente, las de Diocleciano sólo contaban con un 1\%, Curtis 1969. p. x. Tampoco se acuñó plata de manera regular. Sobre este problema, ver Burnett, A., Amandry, M., Ripollès, P.P., Roman Provincial Coinage, Londres/Paris 1992, 1, p. 688 ss.

${ }^{33}$ Wallace, S. Leroy, Taxation in Egypt from Augustus to Diocletian, Princeton 1938, p. 31-47. Rathbone, D.W., "The Weight and measurement of Egyptian grain», ZPE S3, 1983, 26575.; Howgego 1992, p. 23. 




Figura 2. Pompeya, Casa de Meleagro (Regio V1. 9. 13). Napoles, Musco Nazionale, (1 oto DAl Rom, n" neg.: 6f-4225)

traban en Egipto estaban obligados a cambiar su moneda por la alejandrina nada más llegar a puerto ${ }^{34}$. De hecho, salvo raras excepciones, no se han encontrado monedas alejandrinas fuera de Egipto.

En suma, la moneda acuñada en Alejandría estaba destinada, en primer lugar, al salario de los oficiales del gobierno, al de la guarnición permanente y al de las tropas temporales estacionadas en Alejandría; en segundo lugar, al comercio interno de Alejandria y al de ésta con otras ciudades egipcias; en tercer lugar, a la difusión de la propaganda imperial dentro de Egipto.

Dado pues, que la imagen monetal de Alejandria no saldria fuera de Egipto, el conflicto entre dos imágenes iguales y oficiales seria inexistente.

Ahora bien, el siguiente problema que se plantea es la razón por la cual se utiliza en un momento dado esta fórmula iconográfica. La respuesta está en el principal destinatario de la moneda, es decir, el ejército. Durante el siglo I d.C. habia dos legiones establecidas de forma permanente en el doble campamento de Nicópolis, en Alejandría: la Legio III Cirenaica y la Legio XXII Deijotariana ${ }^{35}$, ambas nutridas, en gran parte, de soldados procedentes de la Legio III Augusta, establecida en África.

\footnotetext{
3 West. L.C.. Johnson, A. Ch. Currency in Roman and byzantine Egypt, Princeton 1944, p. 89: Howgego 1992, p. 11.

3) Devijuer, H., L'Egypte et I'histoire de I'armée romaine", Atti del Colloquio internazionale "Egitto e Storia antica. Dall Ellenismo all Ettá araba. Bologna 1987. p. 42.
}

Ya hemos señalado que la primera vez que aparece la imagen femenina con la piel de elefante y la leyenda ALEXANDRIA es con las tetradracmas de vellón neronianas. Pues bien, fue precisamente en tiempos de Nerón cuando encontramos una alta concentración de soldados africanos en las filas de ambas legiones, especialmente en la Deijotariana. A través de la prosopografia sabemos de la existencia de más de 2000 soldados establecidos en Alejandria en el verano del 66 d.C. ${ }^{\text {th }}$, destinados probablemente a las campañas caucasianas o a aplacar la revuelta de los judios de Alejandria.

Esta densidad de individuos de origen africano en el ejército, si bien, con el tiempo, encontró equilibrio con la de otras etnias, se mantuvo en un nivel elevado hasta tiempos de Trajano y Antonino Pio. En el 108 d.C., Trajano desplazó la $/ I /$ Cirenaica a la provincia de Arabia y disolvió la $X X I I$ Deijotariana, pero creó una nueva, la $/ l$ Traiana Fortis ${ }^{37}$, en la que junto a legionarios de origen asiático y egipcio, habia una gran masa de soldados procedentes de Áfricá y Numidia ${ }^{38}$.

\footnotetext{
3n Sadek, M., "On the Billon Output of the Alexandrian Mint under Nero", Phoenix 20, 1966, p. 135./ Cavenaile,R., "Prosopographie de l'armée romaine d'Egypte d'Auguste à Diocletien". Aegyptus L, 1970, p. 213 ss.

37 Sobre el ejército romano en Egipto, ver Devijver,H., «The Roman Army in Egypt», ANRW II.1. 1974, p. 452 ss.

${ }^{7 *}$ Forni, G., "Estrazione etnica e sociale dei soldati delle Legioni", ANRW II.I, 1974, p. 388 .
} 
Asi pues. teniendo en euenta todo esto podria pensarse, y ésta es mi propuesta, que la imagen con piel de elefante de Alejandria. estuvo inicialmente destinada a dos tipos de receptores: 1) el africano, quien podria asi estar familiarizado con la moneda. y 2) el egipcio, para quien la imagen no resultaria nueva a su tradición iconográfica. vinculada a los monarcas ptolemaicos y que se presentaria como auténtica heredera de la del fundador de la ciudad. La imagen, tendria un doble mensaje; ambiguo. en cierto sentido. Con el tiempo. pasaria a incorporarse al elenco o serie de imágenes referidas a Alejandria y asi, por un cierto hábito visual, se llegaria a identificar esta imagen con la ciudad.

El circulo se cierra, de esta manera. La imagen que la provincia de África adopta como emblema no es otra que la de las reinas ptolemaicas ${ }^{34}$. Esta efigie regresa a Alejandria con un doble significado según las dos etnias receptoras de la imagen: Á frica para los africanos, Alejandria para los egipcios.

Teniendo esto presente, asi como el hecho de que la Alejandria tocada con exuviae elephantis soblo representa una pequeña parte del conjunto de todas las imágenes de Alejandria, podemos proponer como base de trabajo que las personificaciones femeninas que lucen la piel de elefante sobre la cabeza halladas fuera del ámbito egipcio, es decir, destinadas a un público imperial, deben interpretarse como África y no como Alejandria. Un documento que apoya esta idea es, por ejemplo, la pintura pompeyana de la Casa de Meleagro ${ }^{40}$. En este fresco, la figura central, entronizada y portadora de una situla no es otra que Alejandria, mientras que la que está a su flanco izquierdo, con quitón largo y tocada con las exuviae elephantis, es África. (fig. 2).

También al mundo pompeyano pertenecen otras imágenes, objeto de polémica confusión iconográfica, en algunas ocasiones.

Una de ellas es un medallón de aplique en bronce del Museo Nacional de Nápoles ${ }^{+1}$ (fig. 3). Del centro del medallón, dividido en tres círculos concéntricos decorados con molduras, sobresale casi en

\footnotetext{
34 Monedas de Cleopatra II/III de Paphos, del 117 a.C.

${ }^{40}$ (Regio VI, 9, 13). Epoca de Vespasiano. Napoli, Museo

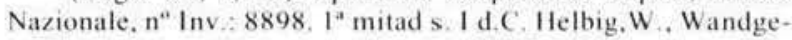
mälde der vom Vesuv verschütteten Städte Campaniens, Leipzig 1886, 223, n०1113; Rizzo,G.E., La pittura ellenistico-romana, Milan 1929, p. 47, tav. LXXXIII; Spinazzola, 1953, 156; Leglay 1981, 254, n51; Catani,E., "Per una iconografia di Libya in età romana». QuadALibia 12, 1987, p. 396.

4) Medallón de aplique. Dim: Alt : $0,29 \mathrm{cms}$. Procedente de Pompeya. Mus. Naz., Nápoles, $n^{\circ}$ inv .: 116188 , sala XC11. $2^{a}$ mitad S. I d.C. Maiuri, Pompei, Roma 1957, 174, fig. I33; Leglay 1981 , $251, n^{\circ} 8$.
}

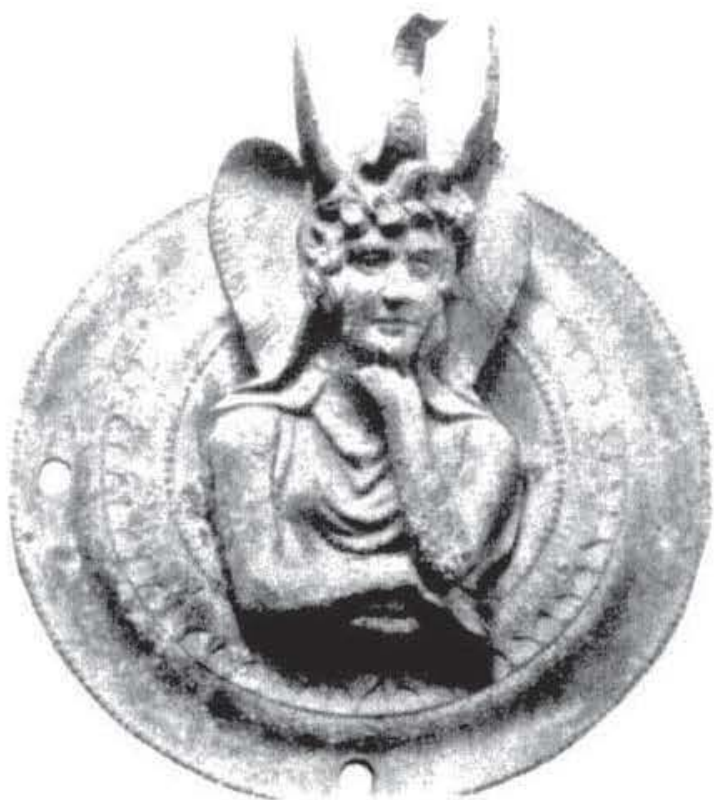

I igura 3. Napoles, Museo Nastonale. (foto L.IMC)

bulto redondo, un busto femenino tocado con la piel de elefante. Se trata de una obra de excelente calidad en la que el juego de luz y sombra que forman los bucles acaracolados del cabello, además del tono naturalista general me impulsa a enmarcarla dentro de la corriente ilusionistica flavia. Esta imagen, identificada por Spinazzola como Alejandria ${ }^{42}$, no es otra que África, y ello no sólo por las razones expuestas más arriba, sino por otro factor a tener en consideración: la actitud. El gesto tipificado de aflicción que transmite la figura, que apoya el mentón sobre la mano, no lo muestra jamás Alejandria, lo que si sucede, por el contrario, con otras de África, como el entalle de Viena ${ }^{43}$ o el relieve de villa Belletti en Roma ${ }^{44}$.

Otra de las figuras erróneamente interpretada como Alejandria o Egipto es la pintura desaparecida de un termopolio de Pompeya ${ }^{45}$ (fig. 4). A ambos lados de la puerta de ingreso están representados, sobre un zócalo amarillo, sendos bustos femeninos colosales. A la derecha, la personificación de Sicilia, con trigo, dos lanzas y tocada con el triskeles. A la

\footnotetext{
4: Spinazrola 1953, fig. 195

t1 Cornalina anaranjada. $(13 \times 9 \times 2 \mathrm{~mm}$. $)$ Viena, Kunsthistorisches Museum, $\mathrm{n}^{\circ}$ inv.: IX B 760. AGO, $\mathrm{n}^{\circ} 1089$.

${ }^{4}$ Leglay 1981, p. 252, n*30; Hölscher, T. Actium und Salamis, Jdl. 99, 1984, p. 209, 210, fig. 12. Salcedo 1991, p. 286.

4' Fresco mural. Dim. de la figura: $0,73 \mathrm{~m}$. de alt. Pompeya, Termopolio de la Reg.II, Ins.II, n.3-5. Desaparecida. Helbig 1886 , 1115: Spinazzola, 1953, p. 157: Leglay 1981, 254, n52.
} 




Figura 4. Pompeya. Termopolos de la Reg.II, Ins.II. n.3-5. Desaparecida. (Foto Spinazzola 1953).

izquierda, el busto de África locada con piel de elefante sobre espigas y acompañada de arco y carcaj. La tienda, unida a una casa particular, pertenecia a un individuo que mantenia relaciones comerciales con África y Sicilia.

Un caso más complejo es el de la famosa pátera de plata perteneciente al tesoro de Boscoreale ${ }^{\text {to }}$, en la que la polisemia de atributos conjugada con la filiación de la pieza han suscitado una larga polémica en cuanto a su definición iconográfica (fig. 5). Las posturas fundamentales en este debate ${ }^{47}$ han sido

\footnotetext{
th Plata parcialmente dorada. Dim: alt., $6 \mathrm{cms}$; diam., 22.5 cms. peso, 643,7 gr. Procedente de la villa de Boscoreale, Pompeya. Paris, Museo del Louvre, inv, $n^{\circ}$ AGR Bj 1969, 20-40 d.C. Heron De Villefosse. A. "Le trèsor de Boscoreale», MonPiot 5, 1899. p. 39.43. pl.1: p. 177-182; Toynbee 1934, pl. XXII, 3: Hinks, R. "Myth and Allegory in Ancient Artw, Studies of the Warburg Inxtitute 6. London 1939, p. 69-70; Helbig. W., Speier, H. Führer durch die äffentichen Sammlungen klassischer Al. tertümer in Rom. 1963-72, III. n. 2122: Strong.E., Greek and Roman Gold and Silver Plate, London 1966, p. 151, pi. 36 B: Leglay $1981, \mathrm{n}^{\circ}$ 55; Baratte, F., Le trésor d'orfevrerie romaine de Boscareale. Louvre, Paris 1986, p. 68-80.: Di Maro, F., "La vittoria di Azio ed it tesoro di Boscoreale. Sy/va Mala 8. 1987. pp. 19-24; Boscoreale 1988, p. 27. 57. passim; Ostrowski 1990. p. 9: Salcedo 1991, p. 289.

* La distintas posturas han sido ya expuestas en Salcedo 1991. pp. $289-290$.
}

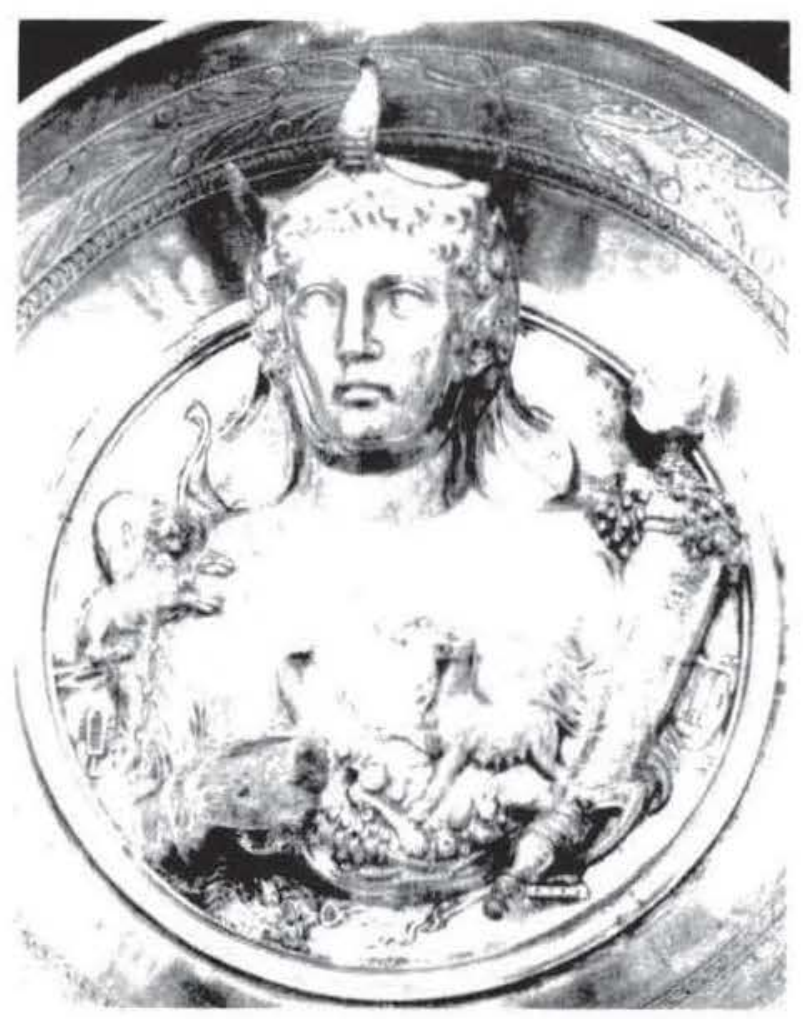

Figura 5. Boscoreale. Pompcya. Paris, Museo del Louvre. (Foto F. Baratte)

considerarla África o Alejandria ${ }^{4 k}$. J. Ostrowski, por su parte, interpreta la figura de la pátera, bien como África, en representación genérica de todo el norte continental, bien como Egipto ${ }^{40}$. De todas estas propuestas, la identificación con Egipto es de todo punto descartable, ya que esta provincia nunca se presenta en la iconografia con la piel de elefante. Cuando lleva tocado, se trata de un loto.

Sobre su definición como Alejandria hay que tener en cuenta lo señalado más arriba: que Alcjandria sólo lleva las exuviae elephantis en las monedas de circulación egipcia. Generalmente la ciudad luce corona torreada o va tocada con espigas o con una proa de barco. Junto a esto hay que tener en cuenta que la pátera pertenecia a un individuo asentado en Boscoreale y que todo el tesoro, aunque privado, tenía un marcado carácter oficial.

th Las primeras interpretaciones fueron las de Collignon y Perdrizet, quienes definieron la imagen como la personificación de Alejandria, Collignon.M., "L'Afrique personifiè Statuette provenant d'Egypte acquise par Jean Masperom, MonPiot, XXII, $2^{\circ} \mathrm{vol}$. 1918. Siguieron las de Heron de Villefosse. Helbig y Gell, que la identificaron como Africa.

49 Ostrowski 1990, p. 96, fecha la pátera en época de Augusto, sin atender al hecho de que se trata del retrato de Cleopatra Selene. 
Pero además, hay otros puntos a considerar. Uno de ellos es que Alejandría no era una divinidad, lo que sí pudo haber sido Africa, o al menos, haber gozado de un cierto sentido religioso. Todos los elementos, sin embargo, que aparecen rodeando a la figura, son una clara referencia al mundo religioso. Es cierto que algunos de ellos, como el uraeus y el sistro, en tanto atributos de Isis, acompañan también la personificación de Alejandria, aunque no de manera exclusiva. La propia África los lleva en algunas imágenes de monedas adrianeas. Pero también hay que tener en cuenta los otros atributos. Todos hacen referencia a divinidades del panteón grecoromano, si bien muchos de ellos están presente en la iconografia de raigambre púnica norteafricana: delfín, león, pantera, cuarto creciente, sistro, uraeus $^{50}$.

Es decir, todos los elementos hacen referencia a ese universo iconográfico africano que asocia la religión greco-romana con la semita. Las alusiones. por ejemplo, al sol y a la luna pueden interpretarse como referencias a Iuno Caelestis, máxima divinidad, junto a Saturno, del panteón romano africano. Incluso los atributos propios de Diana - arco y carcaj-se pueden interpretar de la misma manera, ya que Tanit se asimiló a la Artemis itálica ${ }^{5.1}$.

Así pues, teniendo en cuenta: 1) que la imagen femenina con piel de elefante ya está definida como África en el siglo I a.C.; 2) que gran parte de los atributos de los que se acompaña están presentes en la iconografia púnica norteafricana; 3) que algunos de ellos son propios de África; 4) que la imagen de Alejandría con piel de elefante es un fenómeno prácticamente local, y 5) que el programa iconográfico del tesoro de Boscoreale responde a patrones oficiales, podemos concluir que la imagen de la pátera es la personificación de África.

Llegados a este punto, es necesario considerar un factor adicional pero de gran importancia para la valoración general de la pieza. La figura representada, por su dignificación y la superabundancia de atributos, excede la tónica general de las imágenes de África. Como ya sugiriera Linfert ${ }^{52}$, se trata del retrato divinizado de Cleopatra Selene. Esta ima-

\footnotetext{
${ }^{50}$ Los vemos en las acuñaciones de los reinos de Numidia y Mauritania, Mazard, J., Corpus Numorum Numidiae Mauretaniaeque, Paris 1955 , passim.

s1 Picard G. Ch., Les Trophées Romains, Paris 1957, p. 64 s.

${ }^{22}$ Linfert, A., "Die Tochter - nicht die Mutter. Nochmals zur "Afrika» Schale von Boscoreale", en Alessandria e il mondo ellenistico-romano, Studi in onore di Achille Adriani, Roma 1984. pp. $351-358$, donde compara la figura de Boscoreale con la imagen de Cleopatra Selene junto a Juba Il en el camafeo Gonzaga,
}

gen seria, por una parte, continuadora de las tradiciones retratisticas de los monarcas ptolemaicos, como sucede con Cleopatra II/III en las monedas chipriotas de Pafos del 117 a.C. ${ }^{33}$. Por otra parte, hay que recordar que Cleopatra Selene fue la esposa de Juba II, rey de Mauritania, en definitiva, de un reino africano vasallo de Roma y que utilizaba la misma imagen emblemática que la provincia romana. Si además tenemos en cuenta todos lo elementos que aparecen en la pátera, podemos afirmar que la figura no es otra que la reina Cleopatra Selene divinizada y representada, tras su muerte, como África.

En resumen, la figura de la pátera es la personificación de África, con los rasgos fisonómicos de Cleopatra Selene, reina de Mauritania, es decir, de una de las naciones africanas. Con ello continúa la tradición de otras reinas ptolemaicas que se vistieron con la piel de elefante, como alusión simbólica indirecta a Alejandro, fundador de su dinastia. Como reina de una nación en la que se practicaba la religión púnica, se acompaña de atributos de las divinidades de dicho panteón; como descendiente de egipcios y transmisora del culto isíaco a Mauritania, lleva consigo elementos de la religión egipcia ${ }^{54}$. Por la educación romana recibida en la corte, incorpora los atributos de las principales divinidades del panteón romano. Estariamos ante un retrato de Cleopatra Selene, divinizada como África Panthea.

La pieza es una obra netamente romana aunque tenga sus precedentes estilísticos en la toréutica alejandrina. Su carácter suntuario se corresponde con el lujo propio de la corte de Juba II de Mauritania y de su hijo Ptolomeo, quien fue probablemente el que encargó la pátera, pasando a formar parte del tesoro de la corte imperial y posteriormente, como regalo, al igual que otros vasos del tesoro, a manos del dueño de la villa de Boscoreale.

Las piezas sobre las que hemos detenido nuestra atención no son más que un ejemplo aplicativo del

o en el de Berlín (Staatliche Museum Charlotenburg), en el que aparecen, ver Kyrieleis, «Der Kameo Gonzaga», Bjb 171, 1971, 173 ss., Fig. 10; Fittschen,K., Die Bildnisse der mauretanischen Könige und ihre stadtrömischen Vorbilder"), $M M 15,1974,168$, 43. Anteriormente fue identificada con Cleopatra VII, ver Della Corte, M., Cleopatra, M. Antonio e Ottaviano nelle allegorie storico-umoristiche delle argenterie del tesoro di Boscoreale, Pompeya 1951; Charbonneaux.J., "Un portrait de Cleopâtre au musée de Cherchel». Libyca II, 1954, p, 49-63.

s3 Cleopatra I de Egipto y otra sin identificar. ver Kraeling, C.H., Ptolemais, City of the Libyan Pentapolis, Chicago 1962, p. 180. Cleopatra III y IV, Paphos 117 a.C.

54 Gsell, S., "Les cultes égyptiens dans le nord-ouest de I'Afrique". RHR 59, 1909, I, p. 145; Picard, G. CH., Les Religions de l'Afrique Antique, París 1954, p. 224. 
discurso inicial de este trabajo. Hay y, sobre todo. puede haber casos similares en los que se plantee de nuevo la duda con la que empezamos este articulo. Mi propuesta de que todas las imágenes femeninas con exuviae elephantis, contextualizadas en un ambiente extraegipcio, son Africa no pretende ser una fórmula fija. Lo que si creo es que funciona como una premisa - que por su carácter histórico- puede constituir una base sólida para el análisis ulterior.

El caso de Alejandría es único. No lo vemos en el resto de las provincias, pero es que Alejandria y Egipto son un caso excepcional frente al resto del Imperio. El emitir una imagen oficial, coincidente con otra imagen también oficial, responde, como hemos propuesto a dos objetivos distintos pero confluyentes en el espacio y en el tiempo. Ambos tienen como punto de mira la comunicación visual con dos comunidades o etnias: 1) la africana asentada en Alejandría, y 2) la propia egipcia.

\section{ABREVIATURAS BIBLIOGRÁFICAS}

$A G O$

$B M C R R$

$B M C R E$

BMC Alexandria Poole, R.S., A Catalogue of the

Bowman/ Rathbone 1992 Greek Coins in the British Museum. Catalogue of the Coins of Alexandria and the Nomes. Londres 1892.

Zwierlein-Diehl, E., Die antiken Gemmen des Kunst-Historischen Museums, Wien I-II (1973-1979).

Grueber, H. A., Coins of the Roman Republic in the British Museum, Londres 1910.

Mattingly, H., Carson, R. A. G., Coins of the Roman Empire in the British Museum, I-VI, London 1923-1962, repr. 1965-1976

Bowman, A. K., Rathbone, D., "Cities and Administration in Roman Egypt», JRS 82, 1992, pp. 107-127.
Daszewski 1986

Dattari 1901

Gardner 1888

Howgego 1992

Jentel 1981

Leglay 1981

Ostrowski 1990

RIC

$R R C$

Salcedo 1991

Spinazzola 1953

Toynbee 1934
Daszewski,W. A., «La personification et la Tyche d'Alexandria», $B C H$ Suppl. XIV, 1986, pp. 299-310.

Dattari, G., Monete Imperiali Greche, Numi Augg. Alexandrini I-II, 1901.

Gardner, P., «Countries and Cities in Ancient Art”, JHS 9, $1888,47 \mathrm{ss}$.

Howgego, Ch., «The Supply and the Use of Money in the Roman World", JRS 82 , 1992, pp. 1-31.

Jentel, M. O., «Alexandria», en LIMC I, 1981, pp. 488-494.

Leglay, M., "Africa», LIMC I, 1981.

Ostrowski, J., Les personifications des provinces dans l'Art Romain, Travaux du Centre d'Archeologie Mediterranéenne de l'Academie Polonaise des Sciences, 27, 1990.

Mattingly, H., Sydenham, E. A., Sutherland, C. H. V., Webb, P. H., Perace, J. W., Brunn, P. M., The Roman Imperial Coinage, vol. I-VII, IX, Londres 1923-1967; repr. Londres 1968-1973. (RIC).

Crawford, $M$. Roman Republican Coinage, Cambridge 1974.

Salcedo, F., «La iconografía de África en época romana: algunos aspectos". AEspA, 64, 1991, pp. 284-292.

Spinazzola, V., Pompei alla luce degli scavi nuovi di via dell'Abbondanza (anni 191023), Roma 1953.

Toynbee, J. M. C., The Hadrianic School. A Chapter in History of Greek Art, Cambridge, 1934, p. 28 y ss. 